\title{
Primary Extranodal, Extralymphatic Hodgkin Lymphoma of the Mandible
}

\author{
Guido Ricardo Gonzalez-Fontal, ${ }^{1}$ Joaquin D. Rosales, ${ }^{1}$ Roberto Jaramillo, ${ }^{1}$ \\ and Andres F. Henao-Martinez ${ }^{2}$ \\ ${ }^{1}$ Department of Internal Medicine and Division of Hematology-Oncology, Department of Pathology, \\ CES University-Fundación Valle del Lili, Carrera 98 \# 18-49, Cali, Colombia \\ ${ }^{2}$ Division of Infectious Diseases, University of Colorado Denver, 12700 E 19th Avenue, Aurora, CO 80045, USA
}

Correspondence should be addressed to Andres F. Henao-Martinez, andres.henaomartinez@ucdenver.edu

Received 23 February 2011; Accepted 3 May 2011

Academic Editor: Robert Peter Gale

Copyright () 2011 Guido Ricardo Gonzalez-Fontal et al. This is an open access article distributed under the Creative Commons Attribution License, which permits unrestricted use, distribution, and reproduction in any medium, provided the original work is properly cited.

Primary extranodal, extralymphatic Hodgkin lymphomas (PEEHLs) are a rare occurrence. When they are encountered, they become diagnostic challenges. We are describing the uniqueness of a case of PEEHL affecting the mandible with his early response to the available chemotherapy.

\section{Case}

A 68-year-old hispanic male presented with an oral ulcer 1 month after an orthodontic procedure. His complains were mainly pain at the right inner side of the mouth and adjacent ipsilateral facial swelling. There was no fever, weight loss, or other constitutional symptoms referred at presentation. The lesion and facial edema progressively increased over the last 16 months since the initial presentation. Five biopsies and ancillary diagnostic tests were unremarkable. Past history was only positive for cholecystectomy, knee and cataract surgery. He was then hospitalized for further workup.

On arrival, his vital signs were within normal limits, body mass index of 29. The physical examination was only relevant for the presence of an oral ulcer involving the buccal mucosa and extending to the edentulous alveolar ridge in the right posterior mandibular vestibule (Figure 1).

Swelling over the nasogenial sulcus was also noted. There was no palpable lymphadenopathy or organomegaly. Complete blood count was only significant for normocytic normochromic anemia with hemoglobin of $11.5 \mathrm{~g} / \mathrm{dL}$ (12$16 \mathrm{~g} / \mathrm{dL})$. Other tests including C-reactive protein, liver enzymes, creatinine, blood urea nitrogen, and lactate dehydrogenase were normal. Anemia workup was consistent with anemia of chronic disease. T1 MRI enhanced with
Gadolinium on a coronal plane is shown (Figure 2) and depicts a heterogeneous enhancement of an infiltrative lesion located at the internal border of the right mandible associated with changes on the signal intensity of the adjacent bone marrow. Figure 3 (axial T1) also demonstrates altered bone marrow signal intensity of the right mandible with disruption of the external bone cortex caused by infiltration. The soft tissue mass component is located at the buccal and sublingual spaces of the oral cavity. There were no cervical lymphadenopathies detected. Oral lesion biopsy revealed through microscopy extensive infiltration of the mucosa for noncohesive lymphoid cells with classic morphology of Reed-Sternberg (RS) cells in the typical background of small mature lymphocytes, eosinophils, and plasma cells (Figures 4(a) and 4(b)). The immunohistochemistry study of the RS population confirmed the expression of CD30 (Figure 4(c)) and CD15. Epstein-Barr virus was also detected (Figure 4(d)). The RS cells neither expressed CD45, CD20, EMA, ALK, nor T cell markers such as CD3, CD5, CD4, and CD8. Antiviral capsid antigen immunoglobulin (Ig) $\mathrm{G}$ against Epstein-Barr virus (EBV) was positive, antiviral capsid antigen IgM was negative. EBV DNA copy number was negative (normal range: $<10$ copies). Staging studies with chest, abdominal, and pelvis CT scan and bone marrow biopsy indicated no further extension; erythrocyte 


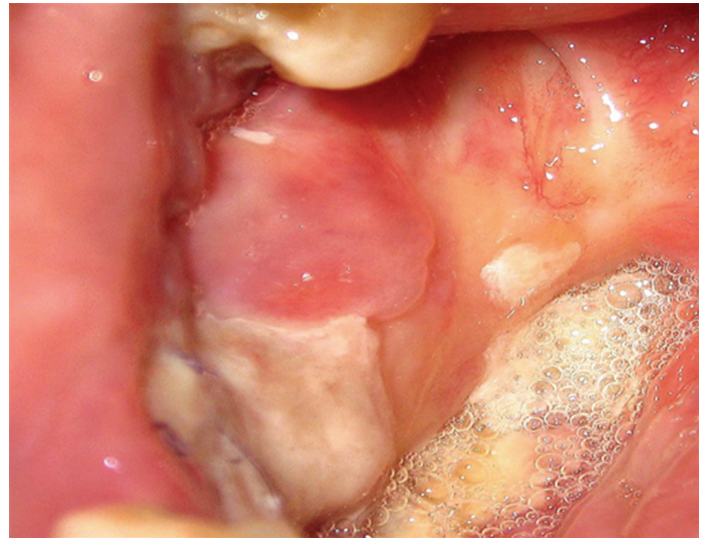

FIGURE 1

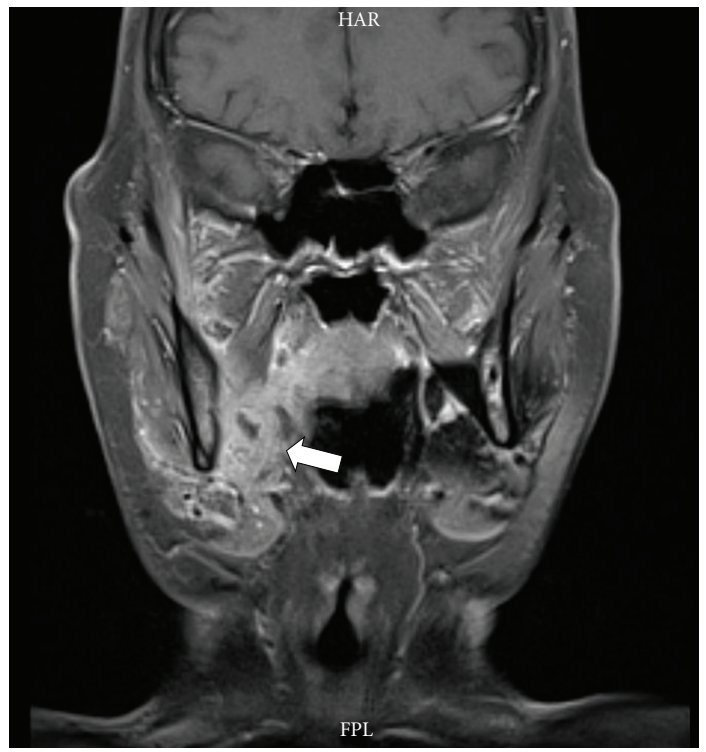

Figure 2

sedimentation rate was $34 \mathrm{~mm} / \mathrm{hr}$ with an albumin level of $3.8 \mathrm{~g} / \mathrm{dL}$. Based on these, a diagnosis of classical Hodgkin lymphoma Cotswold stage IEA was made. He was started on ABVD chemotherapy (doxorubicin, bleomycin, vinblastine, and dacarbazine) with planned duration of two to four cycles before initiation of involved field radiotherapy. Figure 5 (coronal STIR) shows the evolution of the lesion after two cycles of ABVD chemotherapy, with no soft tissue mass present at the moment. Residual changes in bone marrow signal intensity can be seen.

\section{Discussion}

From the subset of malignancies affecting the head and neck region, lymphomas are the second most frequent after carcinomas. From those lymphomas, $80 \%$ to $90 \%$ are NonHodgkin lymphomas and about 4\% represent Hodgkin lymphoma (HL) $[1,2]$. The incidence of HL is estimated to be 7400 new cases per year in the United States, accounting

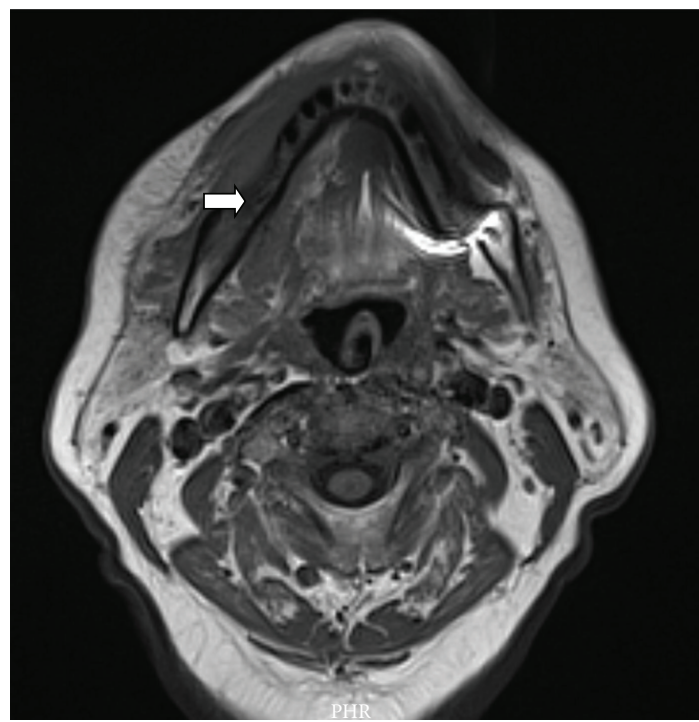

Figure 3

for approximately $30 \%$ of all lymphomas [3]. As well known, most of the HL involves the lymph nodes. However, under some circumstances, those tumors arise from tissues other than the lymph nodes. Trying to define certain anatomical area, the term Waldeyer ring is used to include the lymphoid tissues of the faucial tonsils, nasopharynx, base of tongue, and oropharynx and therefore is considered an extranodal but not an extralymphatic site [4]. HL cases arising from this tissue, although uncommon, are being well characterized [5]. Therefore, the term extranodal, extralymphatic lymphoma has been used to describe the uncommon form of lymphoid malignancy, in which there is neoplastic proliferation at sites other than the expected native lymph nodes and lymphoid tissue, respectively. Due to the difficulty in case definition, the frequency of this type of variation is not well established, nevertheless when sites rich in primary lymphoid tissue such as Waldeyer's ring and spleen are considered extranodal, extranodal lymphomas would represent $25-50 \%$ of all nonHodgkin lymphomas and only $2-5 \%$ of classical Hodgkin lymphomas [6]. In the case herein reported, the lymphoma was localized in the mandible with extension to the buccal mucosa; both considered outside the boundaries of the Waldeyer's ring.

Extranodal, extralymphatic lymphomas from the bone are uncommon, comprising only $8 \%$ of primary malignant bone tumors and they are mainly diffuse B-cell type nonHodgkin lymphomas [7]. This is probably the third case reported of a primary extranodal and extralymphatic oral Hodgkin lymphoma of the mandible $[8,9]$. There is no information on the progression of the first case [8], but the second case relapsed 17 months after diagnosis and involved field radiotherapy of the pleura, spleen, liver, and paraaortic and inguinal lymph nodes, dying 6 months later after five cycles of chemotherapy with MOPP regimen (nitrogen, mustard, vincristine, procarbazine, and prednisone) [9]. Since the applicability of International Prognostic Score is restricted to advanced stage disease [10], a recent study 


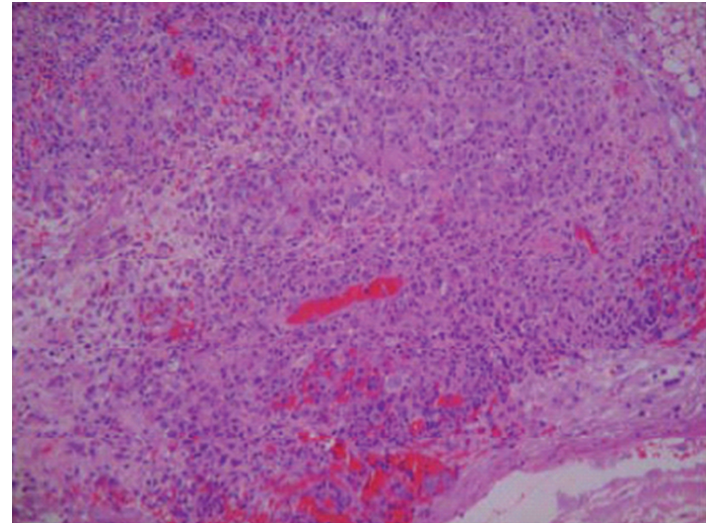

(a)

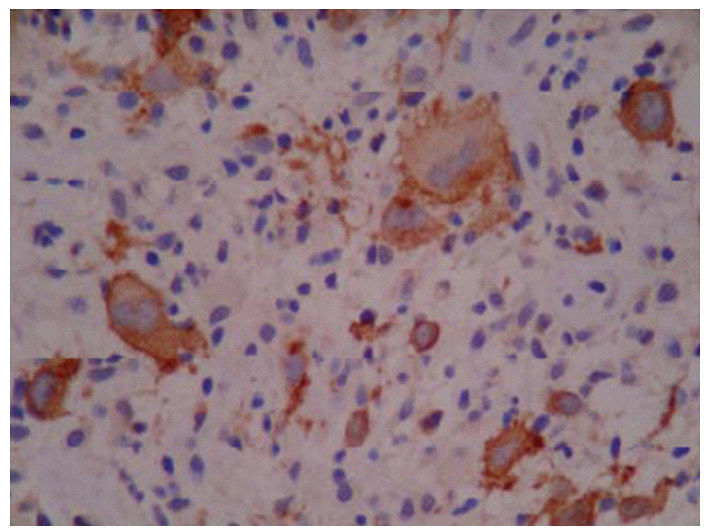

(c)

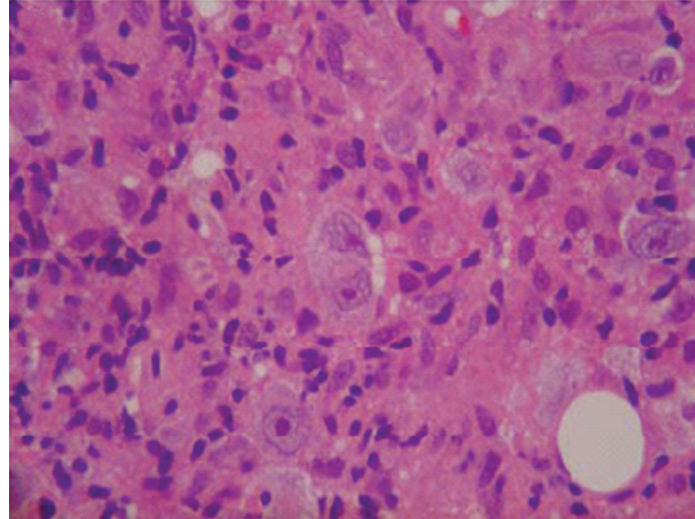

(b)

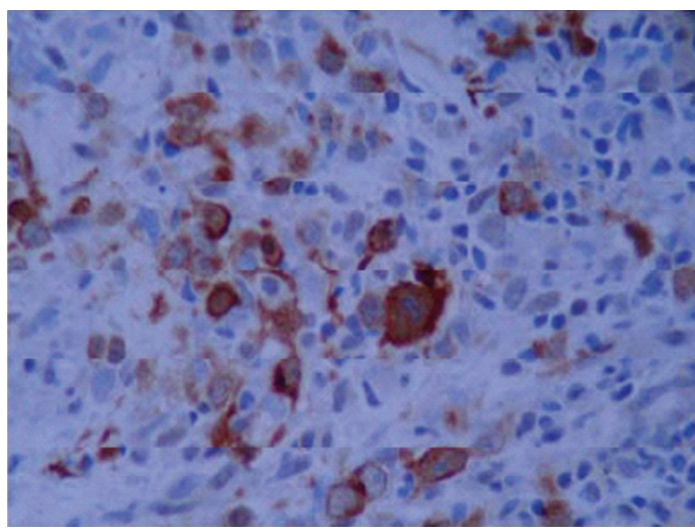

(d)

FIGURE 4

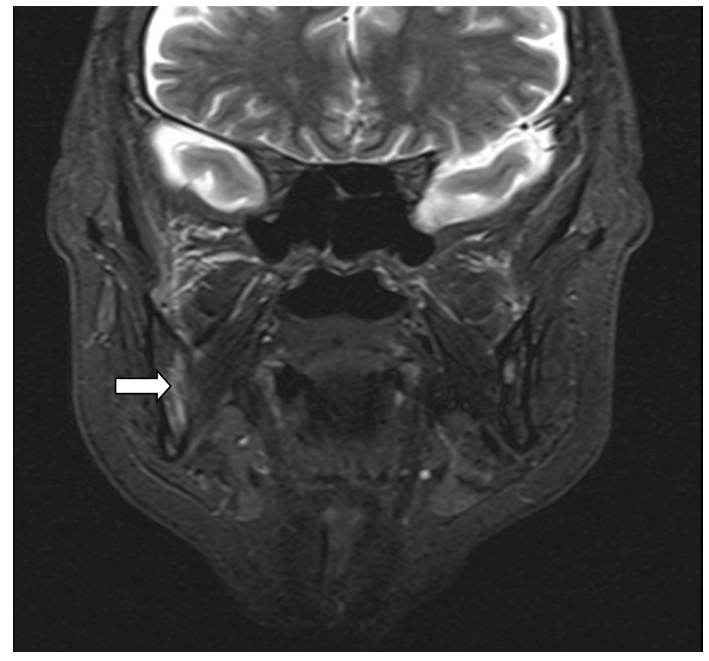

FiguRe 5

showed that the absence of tumor associated macrophages represented by the marker CD68, such in this case, is strongly correlated with $100 \%$ ten-year disease specific survival [11]. Our case was in complete remission 3 months into therapy. We are describing the course of this rare HL presentation and the favorable early response to standard chemotherapy. This displayed the wide clinical spectrum that this type of tumor may encompass. Remarkable still little is known about the survival, prognosis, and effectiveness of the chemotherapy for this rare variant.

\section{References}

[1] A. Urquhart and R. Berg, "Hodgkin's and non Hodgkin's lymphoma of the head and neck," Laryngoscope, vol. 111, no. 9, pp. 1565-1569, 2001.

[2] S. Paryani, R. T. Hoppe, J. S. Burke et al., "Extralymphatic involvement in diffuse non Hodgkin's lymphoma," Journal of Clinical Oncology, vol. 1, no. 11, pp. 682-688, 1983.

[3] B. Schnitzer, "Hodgkin lymphoma," Hematology/Oncology Clinics of North America, vol. 23, no. 4, pp. 747-768, 2009.

[4] C. M. Bacon, "Extranodal lymphomas," Diagnostic Histopathology, vol. 16, no. 2, pp. 82-98, 2010.

[5] P. Quiñones-Avila, A. A. Gonzalez-Longoria, J. H. Admirand, and L. J. Medeiros, "Hodgkin lymphoma involving Waldeyer ring: a clinicopathologic study of 22 cases," The American Journal of Clinical Pathology, vol. 123, no. 5, pp. 651-656, 2005.

[6] D. D. Malis, D. Moffat, and G. W. McGarry, "Isolated nasopharyngeal Hodgkin's disease presenting as nasal obstruction," International Journal of Clinical Practice, vol. 52, no. 5, pp. 343-346, 1998. 
[7] M. L. Ostrowski, C. Y. Inwards, J. G. Strickler, T. E. Witzig, D. E. Wenger, and K. K. Unni, "Osseous Hodgkin disease," Cancer, vol. 85, no. 5, pp. 1166-1178, 1999.

[8] R. F. Steg, D. C. Dahlin, and R. J. Gores, "Malignant lymphoma of the mandible and maxillary region," Oral Surgery, Oral Medicine, Oral Pathology, vol. 12, no. 2, pp. 128-141, 1959.

[9] A. Jamshed, W. F. Allard, W. A. Mourad, and A. Y. Rostom, "Primary Hodgkin's disease of the mandible: a case report and review of the literature," Oral Surgery, Oral Medicine, Oral Pathology, Oral Radiology and Endodontics, vol. 83, no. 6, pp. 680-684, 1997.

[10] D. Hasenclever, V. Diehl, J. O. Armitage et al., "A prognostic score for advanced Hodgkin's disease," The New England Journal of Medicine, vol. 339, no. 21, pp. 1506-1514, 1998.

[11] C. Steidl, T. Lee, S. P. Shah et al., "Tumor-associated macrophages and survival in classic Hodgkin's lymphoma," The New England Journal of Medicine, vol. 362, no. 10, pp. 875$885,2010$. 


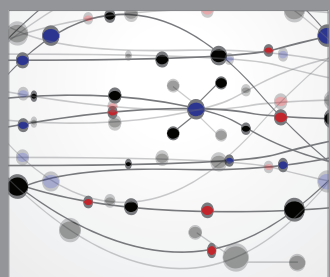

The Scientific World Journal
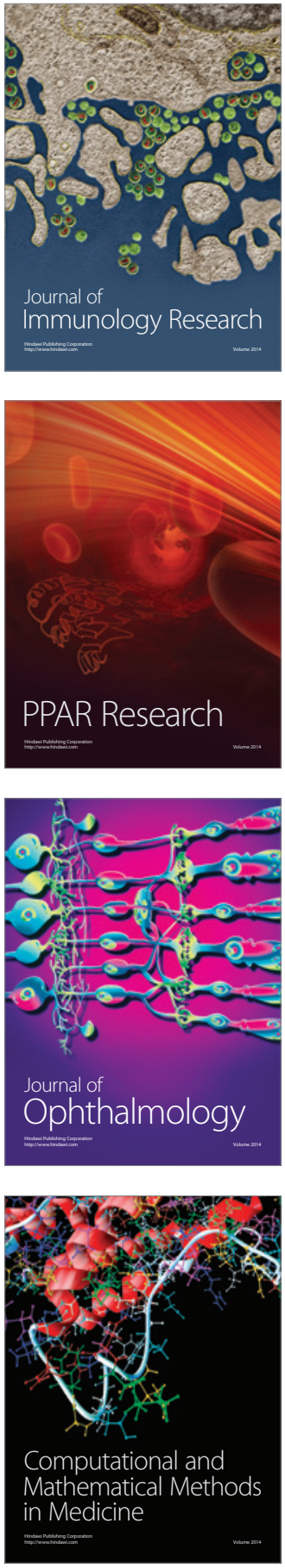

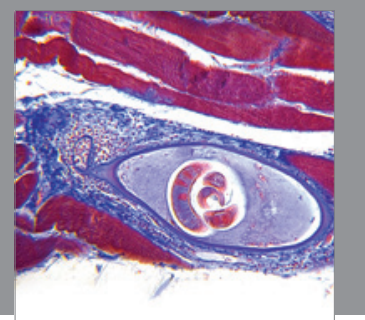

Gastroenterology

Research and Practice
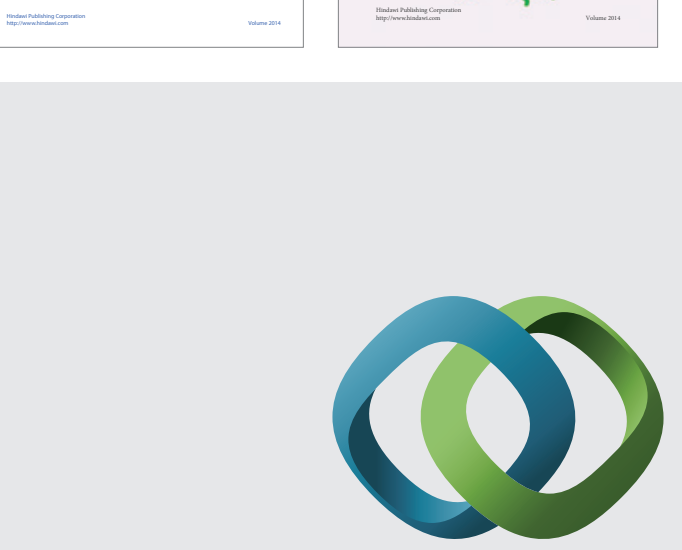

\section{Hindawi}

Submit your manuscripts at

http://www.hindawi.com
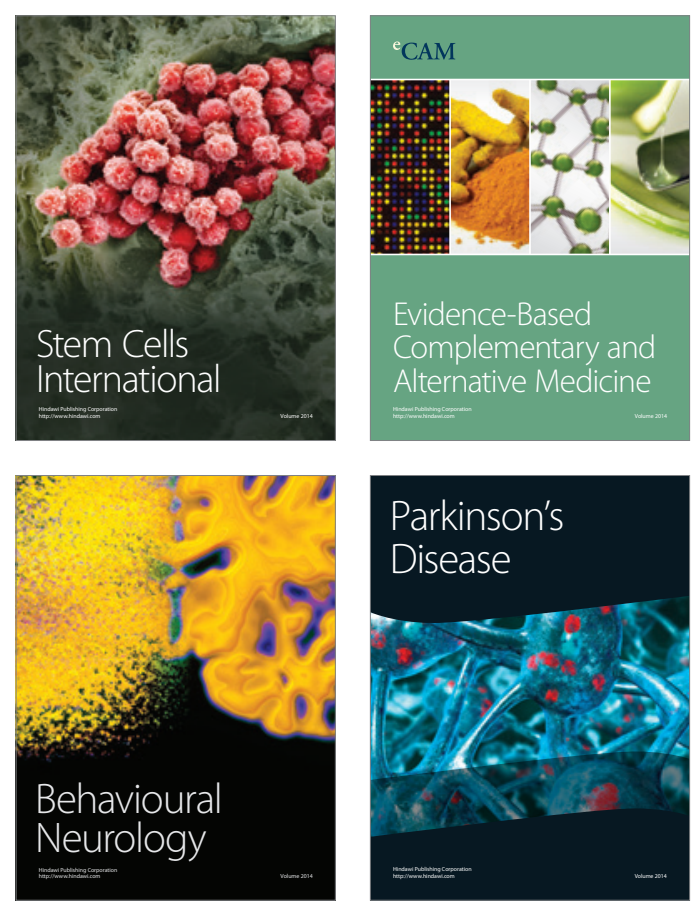

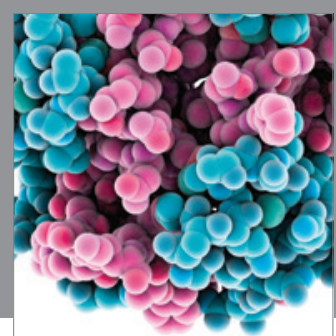

Journal of
Diabetes Research

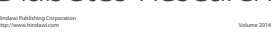

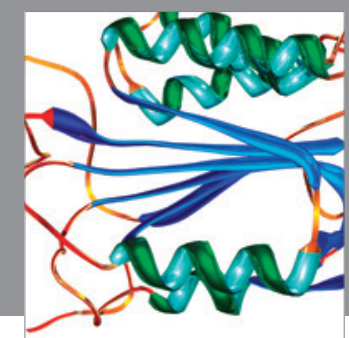

Disease Markers
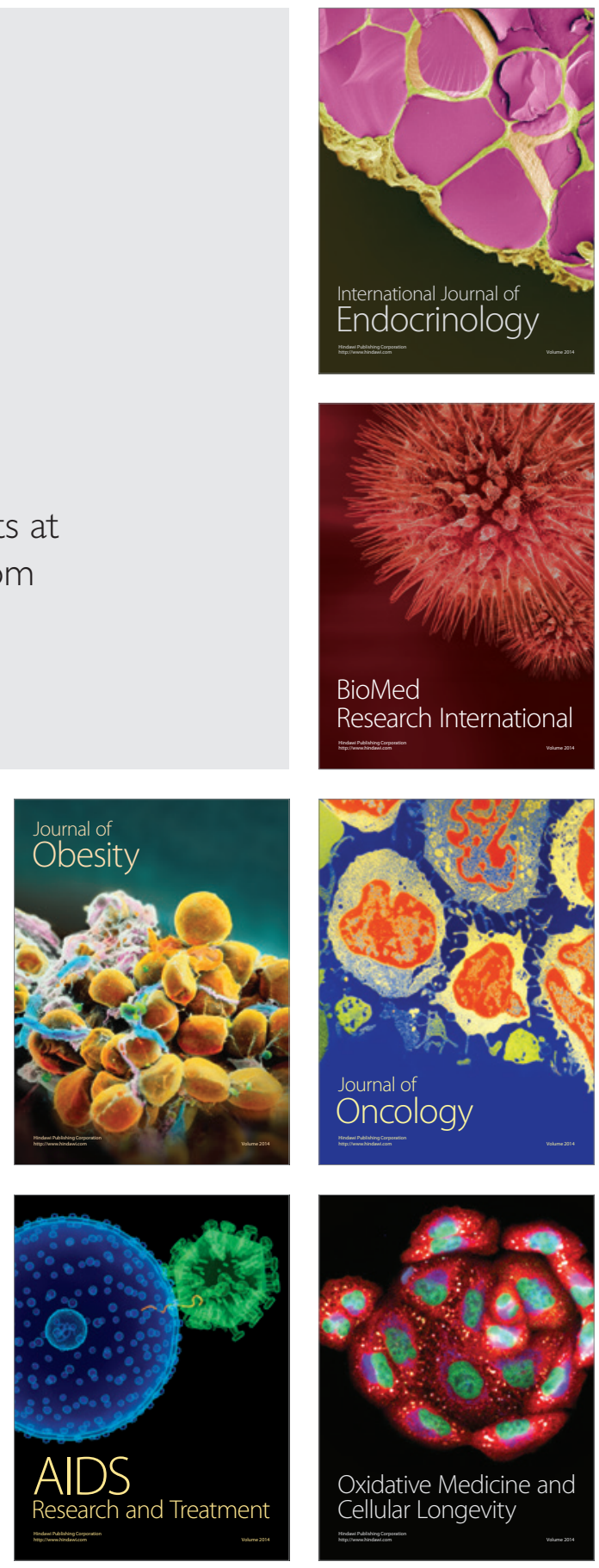